\title{
Development of TiB and nanocrystalline Ti-reinforced novel hybrid Ti nanocomposite produced by powder metallurgy
}

\author{
D. A. Angel ${ }^{1, \star}$ (1), T. Mikó ${ }^{1}$, F. Kristály ${ }^{2}$, M. Benke ${ }^{1}$, and Z. Gácsi ${ }^{1}$ \\ 'Institute of Physical Metallurgy, Metalforming and Nanotechnology, University of Miskolc, Miskolc, Miskolc-Egyetemváros 3515, \\ Hungary \\ ${ }^{2}$ Institute of Mineralogy and Geology, University of Miskolc, Miskolc, Miskolc-Egyetemváros 3515, Hungary
}

Received: 5 October 2021

Accepted: 16 December 2021

Published online:

7 January 2022

(C) The Author(s) 2022

\begin{abstract}
Titanium monoboride (TiB) whisker-reinforced titanium (Ti) matrix composites were produced by powder metallurgy, through vacuum sintering. TiB is formed by thermal decomposition of $\mathrm{TiB}_{2}$ precursor. In addition, a new hybrid composite was developed by admixing nanograined and nanocrystalline (more important) $\mathrm{Ti}$ to enhance the transformation mechanism of $\mathrm{TiB}_{2}$ to $\mathrm{TiB}$ phase. The morphology and particle size of the initial powders, mixtures and the microstructure of the composites have been studied by scanning electron microscopy (SEM). The phase analysis and transformation monitoring were performed by X-ray diffraction (XRD). The sintered composites were also subjected to compressive strength and hardness measurements. According to XRD results, through the addition of nanocrystalline $\mathrm{Ti}$, a probable enhancement of the $\mathrm{TiB}_{2} \rightarrow \mathrm{TiB}$ transformation occurred producing more $\mathrm{TiB}$ whiskers in the hybrid composites. All samples of the hybrid composites exhibited improved yield strength (1365 MPa) and hardness (358 HV) compared to the non-hybrid ones $927 \mathrm{MPa}$ and $254 \mathrm{HV}$, respectively.
\end{abstract}

Handling Editor: Catalin Croitoru.

Address correspondence to E-mail: femangel@uni-miskolc.hu 


\section{GRAPHICAL ABSTRACT}

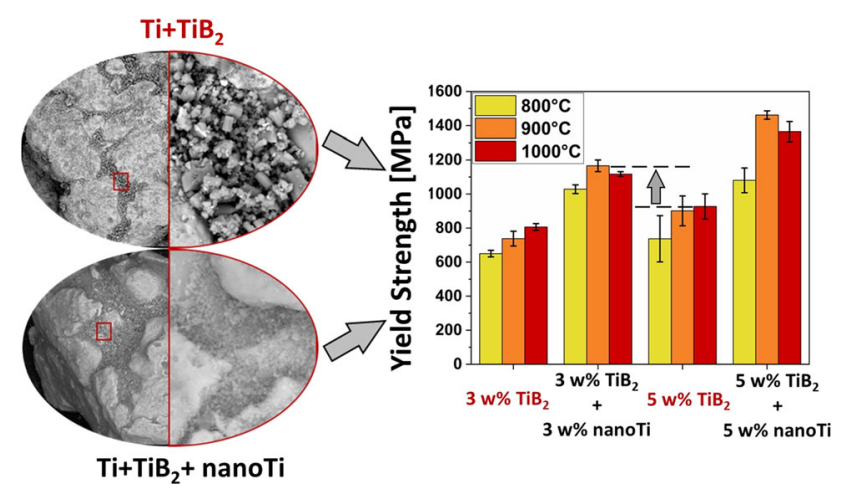

\section{Introduction}

Nowadays, metal matrix composites (MMCs) are becoming one of the most promising materials for applications requiring high specific strength and/or high ductility even at elevated working temperatures. The properties of the MMCs are highly dependent on the interfacial relation between the matrix and reinforcement phase, and one of the best ways to create MMCs with great interfacial relations, are the in situ methods [1]. Titanium is highly popular material for MMCs' production, due to its low density, high specific strength and formability and for its great biocompatibility [2-4]. Since $\mathrm{TiB}_{2}$ has high mechanical properties (hardness, strength) and great thermal stability in absence of $\mathrm{Ti}$, it is a promising candidate not just as matrix material, but also as the reinforcement phase $[5,6]$. Its only disadvantage as matrix material is that it requires high sintering temperature during composite production. Therefore, pairing $\mathrm{Ti}$ matrix with $\mathrm{TiB}_{2}$ for producing Ti-TiB whisker (TiBw)-reinforced type composites can be more beneficial [7]. Such Ti-TiB composites can be used in applications where products and workpieces with high-strength and lightweight are crucial factors [7]. As TiB improves mechanical properties of the composite [8], it can be applied in areas requiring high wear resistance (cutting and machining tools). Furthermore, $\mathrm{Ti}-\mathrm{TiB}$ composites were developed to be applied in intake and exhaust valves in Toyota automotive engines [9]. Yi et al. performed a comparative study between the composites of the Ti$\mathrm{TiB}_{2}-\mathrm{TiC}$ system and composites of the $\mathrm{Ti}-\mathrm{B}_{4} \mathrm{C}-\mathrm{C}$ system, and the authors concluded that the composites of the $\mathrm{Ti}^{-} \mathrm{TiB}_{2}$ system always exhibited improved mechanical properties (elastic modulus, hardness, bending strength) than the composites of the $\mathrm{Ti}-\mathrm{B}_{4} \mathrm{C}$ system [10].

The majority of the $\mathrm{Ti}^{-} \mathrm{TiB}_{\mathrm{w}}$ composites' fabrication is based on the reaction between the Ti matrix and the $\mathrm{TiB}_{2}$ precursor phase according to Eq. 1, without an exact starting temperature:

$\mathrm{Ti}+\mathrm{TiB}_{2} \rightarrow 2 \mathrm{TiB}$

Studies showed that new Ti/TiB interfaces develop from the $\mathrm{Ti} / \mathrm{TiB}_{2}$ interfaces which are sharp and clean, no additional interfacial phases could be observed between them and the TiB is well bonded to the matrix $[1,11,12]$, which gives another reason why to choose $\mathrm{TiB}_{2}$ as a precursor phase for the reinforcing phase. Several papers reported residual $\mathrm{TiB}_{2}$ in the composites after sintering either because of the insufficient kinetic factors [13-15] or because of the excessive amount of $\mathrm{TiB}_{2}$ in the composite $[16,17]$. According to Namini et al., the presence of unreacted $\mathrm{TiB}_{2}$ is most probably due to the short holding time and/or coarse $\mathrm{TiB}_{2}$ particles [13]. On further thought, it means that there is no adequate ratio of $\mathrm{Ti} / \mathrm{TiB}_{2}$ interfaces in the composite to allow the transformation to finish completely for a given sintering time. During sintering, the TiB formation starts on the existing interfaces between the Ti matrix and the $\mathrm{TiB}_{2}$ particles. After the complete decomposition of the 
$\mathrm{TiB}_{2}$ particle, these interfaces cease to exist and new $\mathrm{Ti} / \mathrm{TiB}$ interfaces develop. Due to this, the transformation slows down, because the further TiB formation requires the diffusion of either $\mathrm{B}$ or $\mathrm{Ti}$ atoms from afar [17]. Theoretically, Eq. 1 reaction can be accelerated by introducing new $\mathrm{Ti} / \mathrm{TiB}_{2}$ interfaces through the addition of nanocrystalline Ti particles to the micron-sized system. According to the literature, no research papers have been conducted to examine

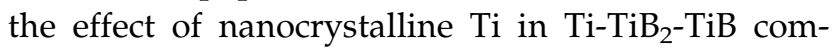
posites. Therefore, the aim of this paper is to develop a novel, hybrid composite, in which the nanocrystalline $\mathrm{Ti}$ phase is added to enhance the $\mathrm{TiB}_{2}$ transformation and to improve the mechanical properties. The aims also include the characterization of the microstructure, mechanical properties of the new composites, and the examination of the nanocrystalline $\mathrm{Ti}$ within the composites. The most appropriate analytical method to investigate the amount of consumed/developed phases is X-ray diffraction, allowing the proper quantification of nanocrystalline phases [18].

\section{Materials and methods}

\section{Sample preparation}

The applied matrix $\mathrm{Ti}$ powder was of $99.4 \%$ purity with nominal average particle size: $150 \mu \mathrm{m}$, produced by Alfa Aesar (product number: 10383), Germany. The additional $\mathrm{TiB}_{2}$ powder was of $99.5 \%$ purity with nominal mean particle size: $50 \mathrm{~nm}$ produced by GoodFellow, England. In addition, nanograined and nanocrystalline Ti powder as reinforcement was also used which was produced by high energy ball milling and was carried out in a steel jar, with steel milling balls (20:1 ball to powder ratio) for $20 \mathrm{~h}$ at $200 \mathrm{rpm}$ speed in ethanol medium. Afterwards, the Ti matrix powder, $\mathrm{TiB}_{2}$ powder and the nanocrystalline Ti powder were dry mixed with a Fritsch Pulverisette 5 type planetary ball mill in a steel milling jar with steel milling balls (10:1 ball to powder ratio) for $30 \mathrm{~min}$ at $100 \mathrm{rpm}$ mixing speed. From the powder mixtures $8 \mathrm{~mm}$ high, $\varnothing 8 \mathrm{~mm}$ cylindrical green samples were made via uniaxially cold pressing by a universal material testing machine (INSTRON 5982, USA). The pressing was carried out with $1.5 \mathrm{GPa}$ pressure, with graphite aerosol as lubricant in vacuum $\left(10^{-2} \mathrm{mbar}\right)$. Before sintering, the tube was flushed with argon then vacuumed several times to remove as much air as possible. The green samples were sintered without external pressure at three different temperatures $\left(800{ }^{\circ} \mathrm{C}, 900{ }^{\circ} \mathrm{C}, 1000{ }^{\circ} \mathrm{C}\right)$ in an electric furnace (SF 16 type Three-Zone Split Tube Furnace, USA), under vacuum $\left(10^{-3} \mathrm{mbar}\right)$ for $2 \mathrm{~h}$ in every case. Figure 1 . shows one of the coldpressed $1 \mathrm{w} \% \mathrm{TiB}_{2}$ content cylindrical sample. All the test pieces looked the same with same diameter, while the height changed on a max $0.2 \mathrm{~mm}$ scale with increasing reinforcer content, as reflected by the relative density values (Results, Fig. 6). After sintering despite the different composition and sintering parameters, the same difference was observed.

The equipments used for the composites' fabrication are shown in Fig. 2, while the composition and the nomenclature of the composites are shown in Table 1. The first letter $\mathrm{C}$ stands for Normal Ti-TiB Composite (without nano-sized $\mathrm{Ti}$ ) and $\mathrm{H}$ stands for Hybrid Composite; the first digit denotes the $\mathrm{TiB}_{2}$ content, while the second digit denotes the sintering temperature. It must be noted that the nanocrystalline Ti was added only to the $3 \mathrm{w} \%$ and $5 \mathrm{w} \% \mathrm{TiB}_{2}$ content, because the effect of the nanocrystalline $\mathrm{Ti}$ in the hybrid composites is expected to be so small, that it would not be detectable via XRD in composites with $1 \mathrm{w} \%$ reinforcement. Also, due to uneven $\mathrm{Ti}$ surfaces, for an effective distribution, more than $1 \mathrm{w} \%$ addition is required.

\section{Examinations}

The starting powders and mixtures have been examined with SEM (Helios G4 PFIB CXe, Thermo Scientific, USA) to describe the initial particles size, the initial morphology and the $\mathrm{TiB}_{2}$ distribution in the mixture. The particle size of the milled $\mathrm{Ti}$ was

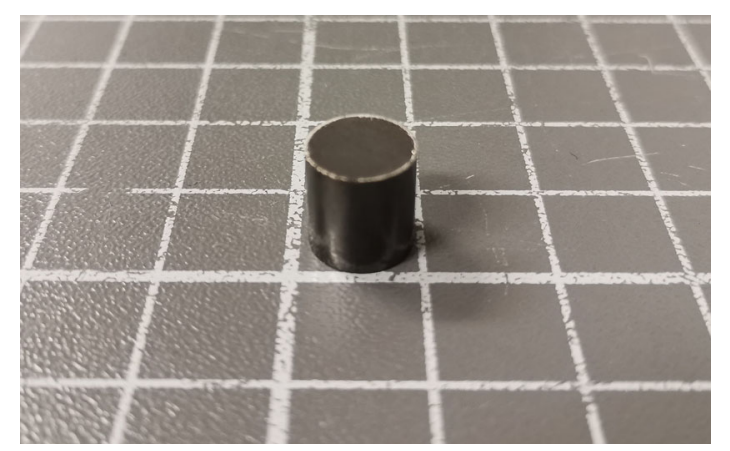

Figure 1 A cylindrical cold pressed Ti-1w\% $\mathrm{TiB}_{2}$ sample (1 mm grid, height of sample is $8.5 \mathrm{~mm}$ ). 


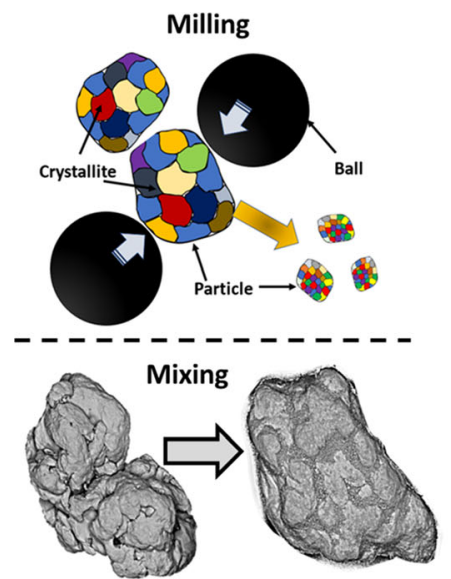

Powder mixing and milling

(a)

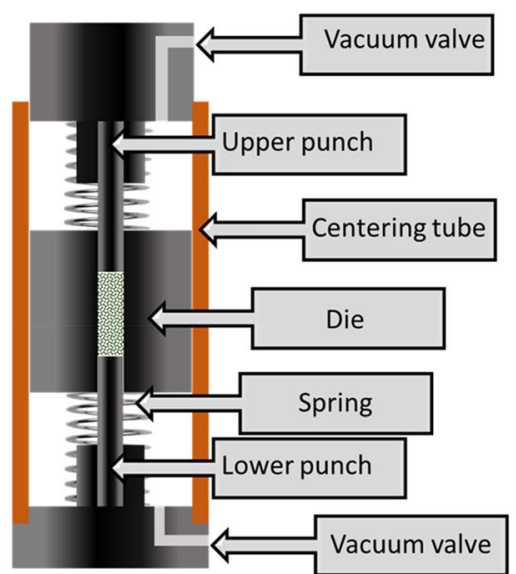

Cold pressing

(b)

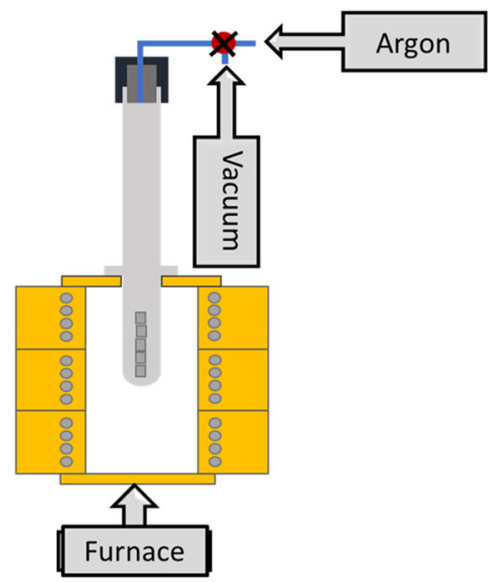

Sintering without external pressure

(c)

Figure 2 The fabrication steps of the composites: $\mathbf{a}$ the difference occurring in the microstructure due to the mixing and milling, $\mathbf{b}$ the toolset of cold pressing and $\mathrm{c}$ the schematic drawing of the sintering furnace.

Table 1 The nomenclature and composition of the Ti$\mathrm{TiB}_{2}-\mathrm{TiB}$ composites sintered at different temperatures

\begin{tabular}{|c|c|c|c|}
\hline Sample & $\mathrm{TiB}_{2}$ content $(\mathrm{w} \%)$ & Nano-sized Ti content (w\%) & Sintering temperature $\left({ }^{\circ} \mathrm{C}\right)$ \\
\hline C- $0-800$ & 0 & - & 800 \\
\hline C-1-800 & 1 & & \\
\hline C-3-800 & 3 & & \\
\hline C-5-800 & 5 & & \\
\hline $\mathrm{H}-3-800$ & 3 & 3 & \\
\hline $\mathrm{H}-5-800$ & 5 & 5 & \\
\hline C-0-900 & 0 & - & 900 \\
\hline C-1-900 & 1 & & \\
\hline C-3-900 & 3 & & \\
\hline C-5-900 & 5 & & \\
\hline H-3-900 & 3 & 3 & \\
\hline $\mathrm{H}-5-900$ & 5 & 5 & \\
\hline C-0-1000 & 0 & - & 1000 \\
\hline C-1-1000 & 1 & & \\
\hline C-3-1000 & 3 & & \\
\hline C-5-1000 & 5 & & \\
\hline H-3-1000 & 3 & 3 & \\
\hline H-5-1000 & 5 & 5 & \\
\hline
\end{tabular}

also determined by a laser scattering particle size distribution analyser (LPSA) (Horiba-LA950V2, UK).

Phase analysis was carried out by XRD on Bruker D8 Discover (USA-Germany) instrument with $\mathrm{Cu} \mathrm{K-} \alpha$ $(1,2)$ radiation $(40 \mathrm{kV}$ and $40 \mathrm{~mA}$ generator settings) in Bragg-Brentano geometry with LynxEye XE-T energy-dispersive position sensitive detector in $1 \mathrm{D}$ $\left(2^{\circ}\right.$ opening) high energy resolution mode. Crystalline phases were identified by Search/Match algorithm in Bruker DiffracPlus EVA software from ICDD PDF2 database. The weight fraction of the phases, $\mathrm{Ti}$, untransformed $\mathrm{TiB}_{2}$ and formed $\mathrm{TiB}$ was calculated with the whole pattern deconvolutionbased Rietveld refinement method [19]. The basic relationships of the method are described by Eq. 2:

$\mathrm{M}\left(S_{i}, x\right)=b\left(S_{i}, x_{b}\right)+\sum_{k=k_{1}}^{k_{2}} I_{k}\left(x_{s}\right) \emptyset\left(S_{i}-S_{k}, x_{p}\right)$

where $x_{b}, x_{s}, x_{p}$, are the background, the structure and the peak shape parameters, respectively, and the $\mathrm{S}_{\mathrm{i}}=2 \sin \theta_{\mathrm{i}} / \lambda_{\mathrm{i}}$. The term $\mathrm{b}\left(\mathrm{S}_{\mathrm{i}}, \mathrm{x}_{\mathrm{b}}\right)$ is a background 
function, $l_{k}\left(x_{s}\right)$ is the integrated intensity of the k-th Bragg reflection and the $\varphi\left(S_{i}-S_{k}, x_{p}\right)$ is a peak shape function. The method relies on the fitting of the measure X-ray diffraction pattern with the calculated (model) patterns of individual phases through the least squares approach. The intensity relations for each point of the model patterns for single phases are calculated by Eq. 3. which contains all crystal structure parameters, instrumental contributions and background scattering:

$y_{c i}=s \sum_{K} L_{K}\left|F_{K}\right|^{2} \emptyset\left(2 \theta_{i}-2 \theta_{K}\right) P_{K} A+y_{b i}$

where $\mathrm{y}_{\mathrm{ci}}$ stands for the calculated intensity at the i-th step, $\mathrm{s}$ is the scale factor, $\mathrm{K}$ represents the Miller indices, $\mathrm{h} \mathrm{k} \mathrm{l}$, for a Bragg reflection. $\mathrm{L}_{\mathrm{K}}$ contains the Lorentz polarization and multiplicity factors, $\varphi$ is the reflection profile function, $\mathrm{P}_{\mathrm{K}}$ is the preferred orientation function, $\mathrm{A}$ is the absorption factor, $\mathrm{F}_{\mathrm{K}}$ is the structure factor for the K-th Bragg reflection and the $\mathrm{y}_{\mathrm{bi}}$ is the background intensity at the i-th step.

Rietveld refinement was carried out in a Bruker TOPAS5 software [20] applying Fundamental Parameters Approach for instrumental profile and NIST SRM 1976 corundum standard for calibration. Crystal structure information (atomic coordinates and parameters) was used from ICSD (Inorganic Crystal Structure Database). During the evaluation, the difference between the measured and calculated patterns is minimized, which is indicated by a difference curve also. Differences are solved by correcting preferred orientation, calculating crystallite size and strain and refining structural parameters (unit cell parameters, thermal parameters) [21].

On the cross section of the sintered samples, microhardness and Brinell hardness (HB) measurements were also carried out. For the Brinell tests, a Wolpert UH930 (China) universal hardness testing equipment was used. The measurements were carried out with $62.5 \mathrm{~kg}$ load, $2.5 \mathrm{~mm}$ steel ball and $10 \mathrm{~s}$ loading time. The microhardness measurement was performed with a Tukon 2100B (USA) type equipment, where for the indentations a $0.2 \mathrm{~kg}$ load was applied for $10 \mathrm{~s}$. The Brinell values were converted to Vickers hardness for comparison. The composites have been also subjected to compressive tests to determine the yield strength and the maximum strain. For the measurement of the strain changes, an AVE200 type extensometer was used. For the tests, 3 parallel samples have been prepared and the average values with the deviation were calculated. These measurements were also performed with the above described universal material testing machine. For the microstructure examination by SEM, the cross sections have been grinded, polished and etched with Kroll etchant $(10 \mathrm{ml} \mathrm{HF}+30 \mathrm{ml} \mathrm{HNO} 3+50 \mathrm{ml}$ distilled water) for 8-10 s.

\section{Results}

The SEM examinations of the powders revealed that the initial Ti particles have sponge-like structure and the (Fig. 3b) sizes agree with the nominal value, while the morphology of the $\mathrm{TiB}_{2}$ is platy and its particle size differs from its nominal size, varying between $\sim 10 \mathrm{~nm}$ and $1-2 \mu \mathrm{m}$ (Fig. 3a). It can be clearly seen in Fig. $3 c$ that the milled $\mathrm{Ti}$ particles formed agglomerates during the long-time milling, and the individual particle size of the milled $\mathrm{Ti}$ is below $\sim 100 \mathrm{~nm}$. The XRD results showed crystallite size in the range of 5-8 $\mathrm{nm}$, indicating that the milled $\mathrm{Ti}$ is both nanograined and nanocrystalline. In Fig. 3d, it can be observed that the small particle sized $\mathrm{TiB}_{2}$ filled up the hollows of the sponge-like $\mathrm{Ti}$, leaving some empty areas. In case of the H-5 composites (shown in Fig. 3e), the nano-sized Ti filled up the remained voids in the $\mathrm{Ti}$ sponge and the voids between the matrix and the $\mathrm{TiB}_{2}$ particles.

The XRD peaks of each phase can be identified on the patterns (Fig. 4); however, the deconvolution process of Rietveld refinement is required for quantitative calculations due to the overlapping of broadened peaks and severe texture produced by pressing and $\mathrm{TiB}$ crystallisation. Table 2 . shows the XRD results of the composites with $5 \mathrm{w} \%$ of initial $\mathrm{TiB}_{2}$ content. At $800{ }^{\circ} \mathrm{C}$, the presence of $\mathrm{TiB}$ is indicated by the broad hump between.

41 and $43^{\circ}(2 \theta)$, in accordance with $10-27 \mathrm{~nm}$ crystallite size and small percentage. At $900{ }^{\circ} \mathrm{C}$, the peaks of TiB are well evidenced, especially at $29^{\circ}(2 \theta)$. The increase in crystallite size is indicated by the more prominent separation of the two peaks at 41.5 and $42.5^{\circ}(2 \theta)$. In parallel with $\mathrm{TiB}$ crystallisation, the formation of very small amount of Fe-monoxide and Ti-monoxide phases is observed, showing similar peaks to the phases given in Fig. 4. However, the peaks are too small and weak for further detailed characterisation and also for the discussion of the role of these phases in the sintering process. 


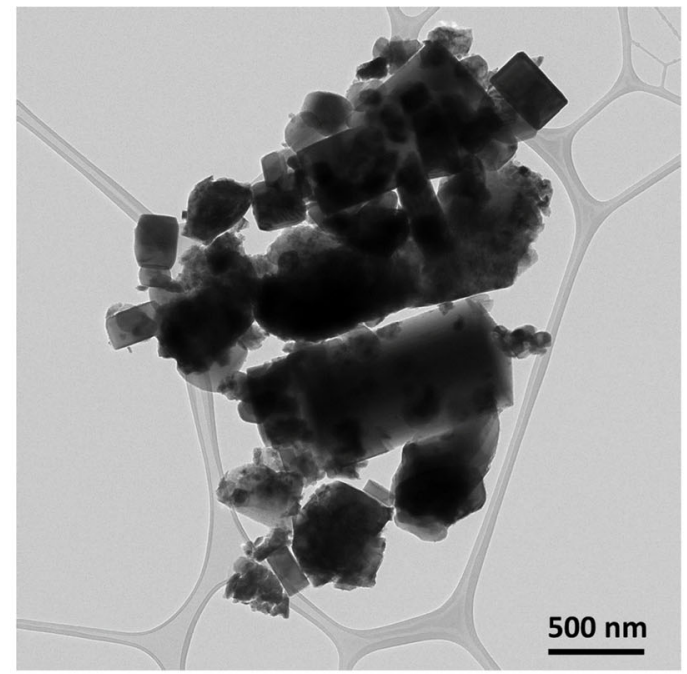

(a) $\mathrm{TiB}_{2}$ particles

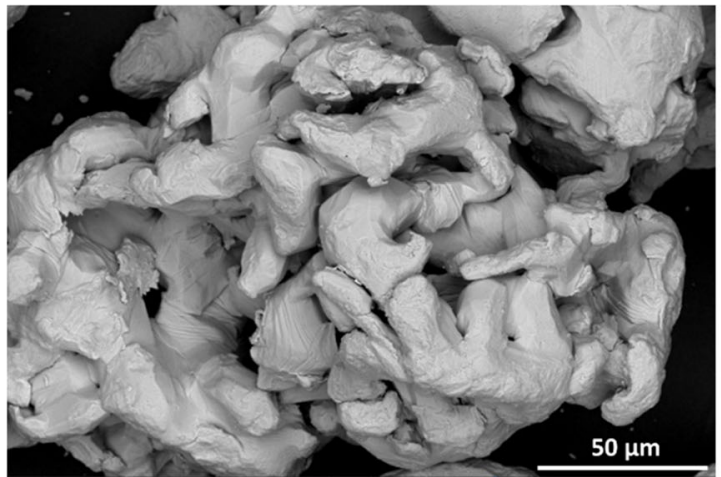

(b) - Ti particle

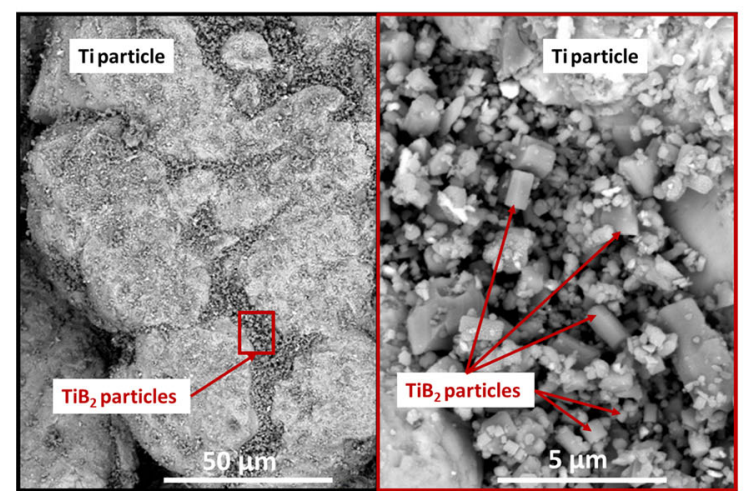

(d) C-5 powder mixture

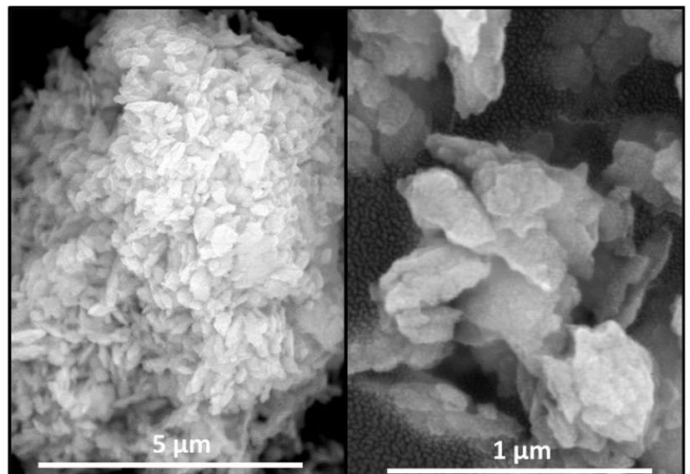

(c) - agglomerate of nano-sized Ti particles

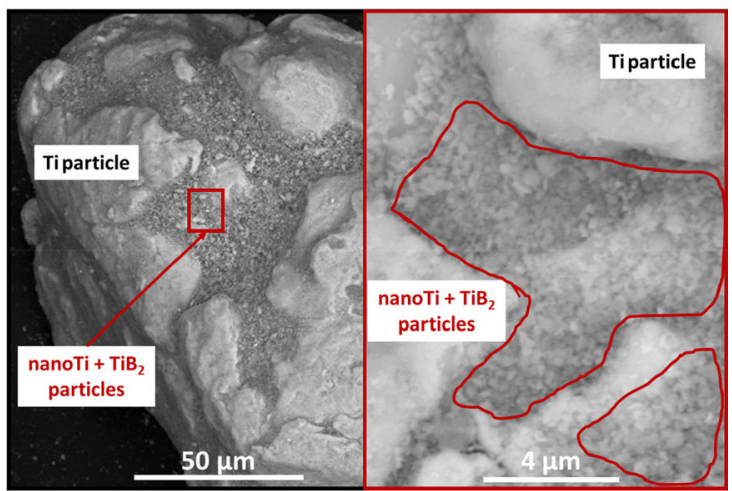

(e) $\mathrm{H}-5$ powder mixture

Figure 3 TEM image of the initial $\mathrm{TiB}_{2}$ powder $\mathbf{a}$, the SEM images of the initial Ti $\mathbf{b}$, milled nano-sized Ti $\mathbf{c}$ powders, and the C-5 $\mathbf{d}$ and H-5 e powder mixtures (SE images).

Nevertheless, the XRD analysis showed different oxides in the composition of both the hybrid and nonhybrid composites. The iron oxide crystallizes from Fe contamination due to milling, most probably capturing the oxygen from the natural passive layer of the Ti particles' surface [22, 23]. The Ti-oxide $\left(\mathrm{TiO}_{1.04}\right)$ is developed from the same passive layer; 


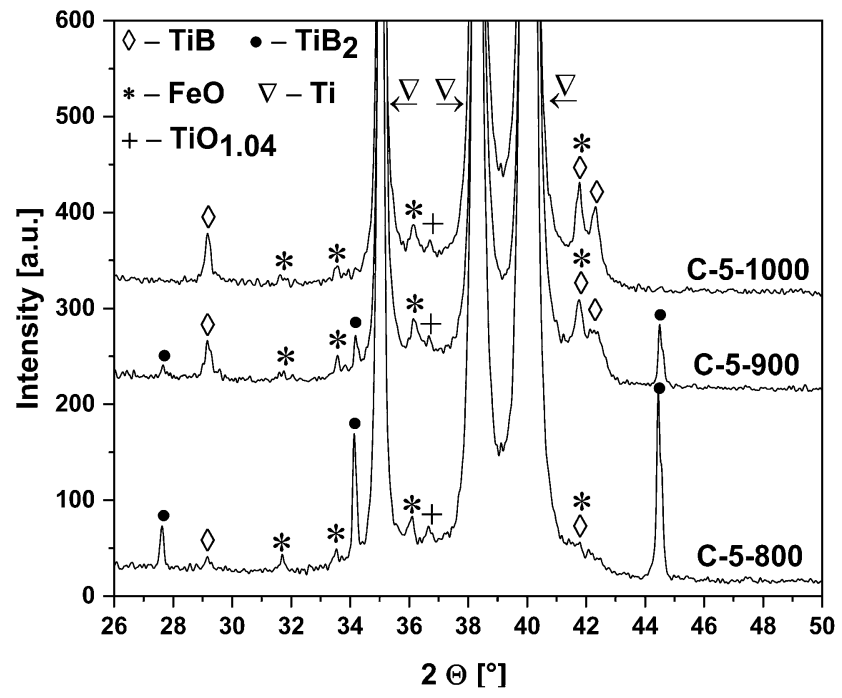

(a)

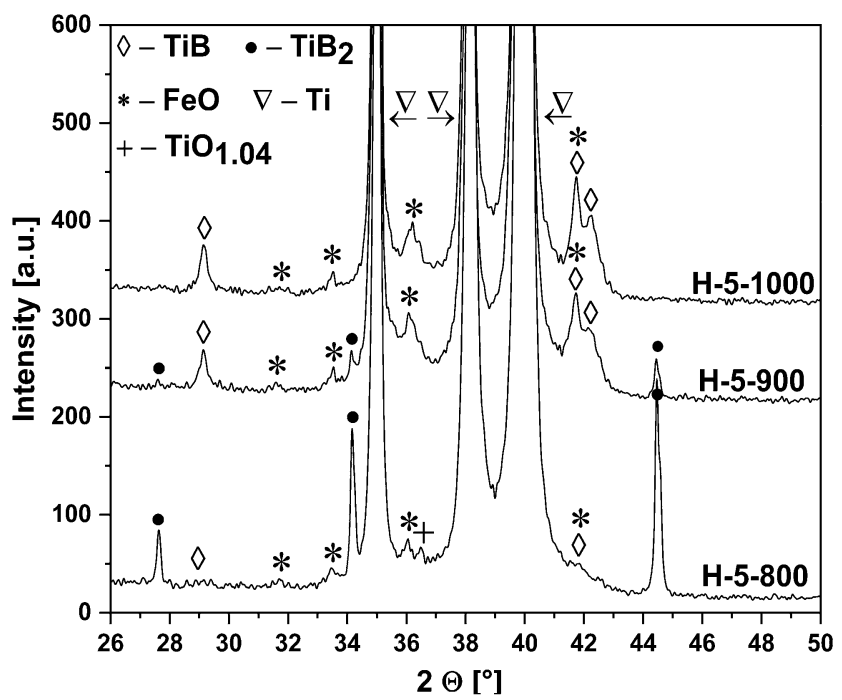

(b)

Figure 4 The identified TiB (PDF-05-0700), TiB 2 (PDF-35-0741), FeO (PDF-06-0615), TiO ${ }_{1.04}$ (PDF-43-1295) and Ti (PDF-44-1294) phases on the XRD patterns (upper part omitted) in case of the C-5 a and H-5 composites $\mathbf{b}$.

Table 2 The $\mathrm{TiB}_{2}$ and $\mathrm{TiB}$ content (weight percentages w\%) evaluated with the Rietveld method, where b.d.l. denotes to below detection $\operatorname{limit}(<0,1 \mathrm{w} \%)$

\begin{tabular}{llllll}
\hline Sample & $\mathrm{TiB}_{2}(\mathrm{w} \%)$ & $\mathrm{TiB}(\mathrm{w} \%)$ & $\mathrm{FeO}(\mathrm{w} \%)$ & $\mathrm{TiO}_{1.04}(\mathrm{w} \%)$ & $\mathrm{Ti}(\mathrm{w} \%)$ \\
\hline $\mathrm{C}-5-800$ & 3.8 & 2 & 1.8 & 0.2 & 92.2 \\
$\mathrm{H}-5-800$ & 3.8 & 2 & b.d.1 & 1 & 93.2 \\
$\mathrm{C}-5-900$ & 1.1 & 6.5 & 0.5 & b.d.1 \\
$\mathrm{H}-5-900$ & 0.9 & 6.9 & 1.3 & 0.7 & 91.9 \\
$\mathrm{C}-5-1000$ & 0 & 8.4 & 0.6 & b.d.l & 90.2 \\
H-5-1000 & 0 & 8.4 & 1 & 0.7 & 91 \\
\hline
\end{tabular}

however, these contaminations do not decrease the mechanical properties, as shown in Figs. 7 and 8.

According to the results, $2 \mathrm{~h}$ of sintering at $1000{ }^{\circ} \mathrm{C}$ is sufficient to complete the $\mathrm{TiB}_{2} \rightarrow \mathrm{TiB}$ transformation. However, at $800{ }^{\circ} \mathrm{C}$ and $900{ }^{\circ} \mathrm{C}$, some of the $\mathrm{TiB}_{2}$ remained after sintering due to incomplete transformation, most probably because of the slower diffusion rate. The remaining $\mathrm{TiB}_{2}$ content is inversely proportional to the temperature, meaning the lower the temperature the more $\mathrm{TiB}_{2}$ remains. It is also apparent that at $800{ }^{\circ} \mathrm{C}$, the same amount of $\mathrm{TiB}_{2}$ transformed to TiB for both non-hybrid (C-5-800) and hybrid (H-5-800) composites. At $900{ }^{\circ} \mathrm{C}$, however, more $\mathrm{TiB}_{2}$ transformed to $\mathrm{TiB}$ in the hybrid composite (H-5-900) compared to its non-hybrid pair (C5-900). It must be noted that such differences in the results are not sufficient for further speculation; however, an explanation is given in the discussion section.

The results of the SEM examination confirm that the reactions took place and $\mathrm{TiB}_{\mathrm{w}}$ were formed. The
$\mathrm{TiB}_{\mathrm{w}}$ length:width ratio can exceed even 10:1, the needles penetrating the $\mathrm{Ti}$ matrix, which is the desired property for improved reinforcing. The growing directions of $\mathrm{TiB}_{\mathrm{w}}$ are the crystallite boundaries and subparticle interfaces, facilitating $\mathrm{B}$ diffusion in the bulk Ti. Figure 5. shows selected textures from the C-5-900 and H-5-900 composites' microstructures, best representing the transformations upon sintering.

The examination reveals also $\mathrm{TiB}$ agglomerates produced during the sintering. The $\mathrm{TiB}_{\mathrm{w}}$ and $\mathrm{TiB}$ agglomerates are indicated via red circles in Fig. 5. However, neither the added nanocrystalline Ti phase nor its effect on the $\mathrm{TiB}_{2} \rightarrow \mathrm{TiB}$ transformation can be observed in SEM images. The diagram in Fig. 6 . shows the relative density values measured before (green) and after sintering (sintered).

The relative density increases with rising sintering temperature and the highest values are achieved at $1000{ }^{\circ} \mathrm{C}$ sintering temperatures in each composition. However, the relative density values decrease as the 


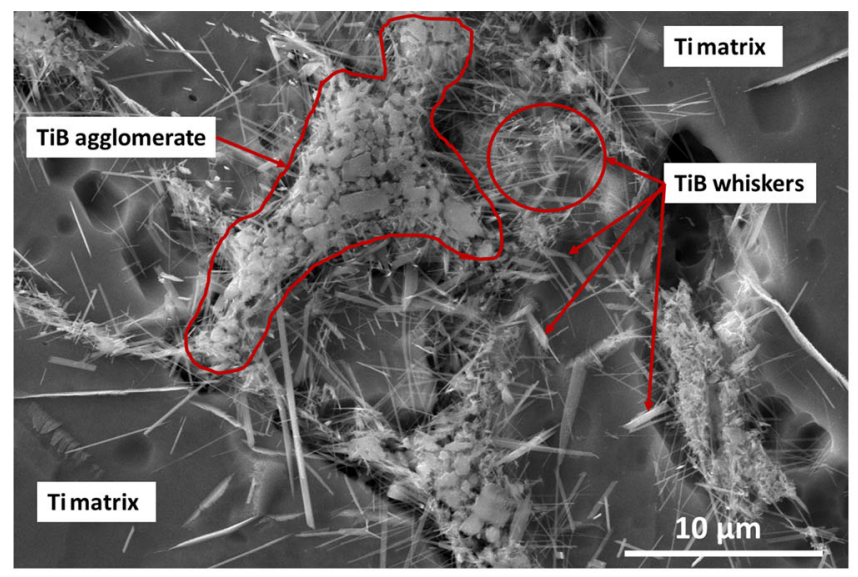

(a)

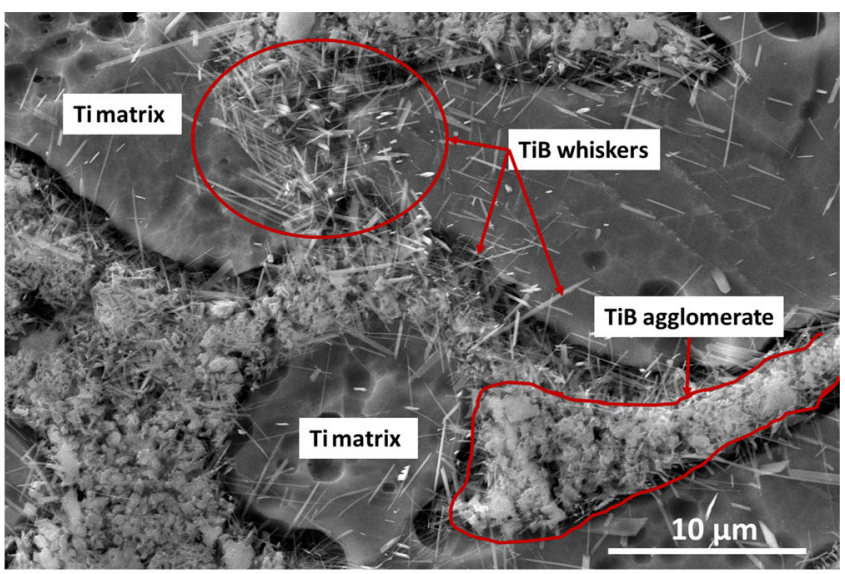

(b)

Figure 5 Microstructure of the C-5-900 a and H-5-900 b composites (SE images).

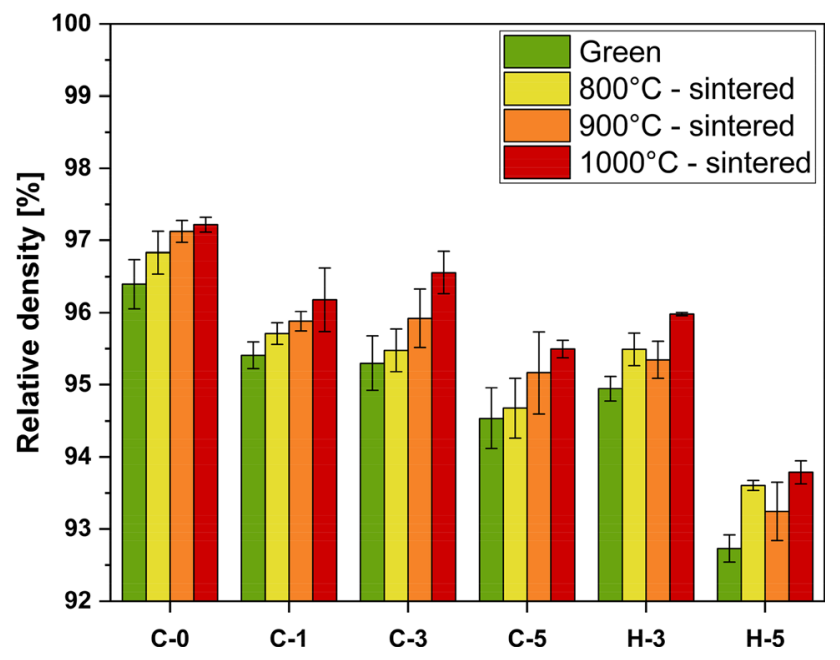

Figure 6 Relative density of the composites before and after sintering.

content of reinforcement phases (initial $\mathrm{TiB}_{2}$ and nano-sized Ti) increases; therefore, the highest porosity in the H-5 composites was observed. Figure $7 \mathrm{a}$. shows the microhardness, while Fig. $7 \mathrm{~b}$. represents the converted [24] Vickers hardness values of all the non-hybrid (C), hybrid (H) composites.

According to the figures, the temperature of sintering has only slight influence on the hardness values, while the total amount of the reinforcement phase greatly affects the final hardness of the composites. It is also evident that the added nanocrystalline Ti improves the hardness values. The results (yield strength and maximum strain) of the compressive tests are shown in Fig. 8.

Comparing the yield strength of the H-5 composites to the $\mathrm{C}-5$ composites (or the $\mathrm{H}-3$ composites to the C-3 composites), the hybrid samples exhibited significantly higher values, almost a cca. 1.5 times increase can be observed. In case of the H-5 composites due to the greatly increased yield strength, the maximum strain of the composites decreased significantly. In case of the $\mathrm{H}-3$ composites, a remarkable maximum strain (cca. 10\%) is still preserved. According to the test results, the nanocrystalline $\mathrm{Ti}$ has a strengthening effect on the H-3 and $\mathrm{H}-5$ composites; however, reaching a certain point in terms of reinforcing phase content, (which is $10 \mathrm{w} \%$ in case of $\mathrm{H}-5$ composites) it makes the composites brittle resulting in low formability (see Fig. 8b). Figure 9. shows the stress-strain curves of the parallel $\mathrm{H}-3$ and C-3 composites sintered at $1000{ }^{\circ} \mathrm{C}$. The curves of the non-hybrid and hybrid composites are similar, but the latter reveals significantly higher stress levels.

\section{Discussion}

During sintering, the initial particles of the Ti matrix attach to each other on the free surfaces, making a compact bulk material. With rising temperatures, the $\mathrm{Ti}+\mathrm{TiB}_{2}=2 \mathrm{TiB}$ reaction occurs, but a sharp offset ${ }^{\circ} \mathrm{C}$ cannot be identified due to the slow diffusion of $\mathrm{B}$. Based on the SEM images, whiskers are formed, and it is safe to say that the developed $\mathrm{TiB}_{\mathrm{w}}$ are well bonded with the matrix particles. It must be noted that according to stoichiometric calculation of Eq. 1, the $\mathrm{TiB}_{2}$ transformation to $\mathrm{TiB}$ increases the total amount of reinforcing phases. For instance, from 5 $\mathrm{w} \%$ of $\mathrm{TiB}_{2}$, a total amount of $8.4 \mathrm{w} \% \mathrm{TiB}$ will form in 


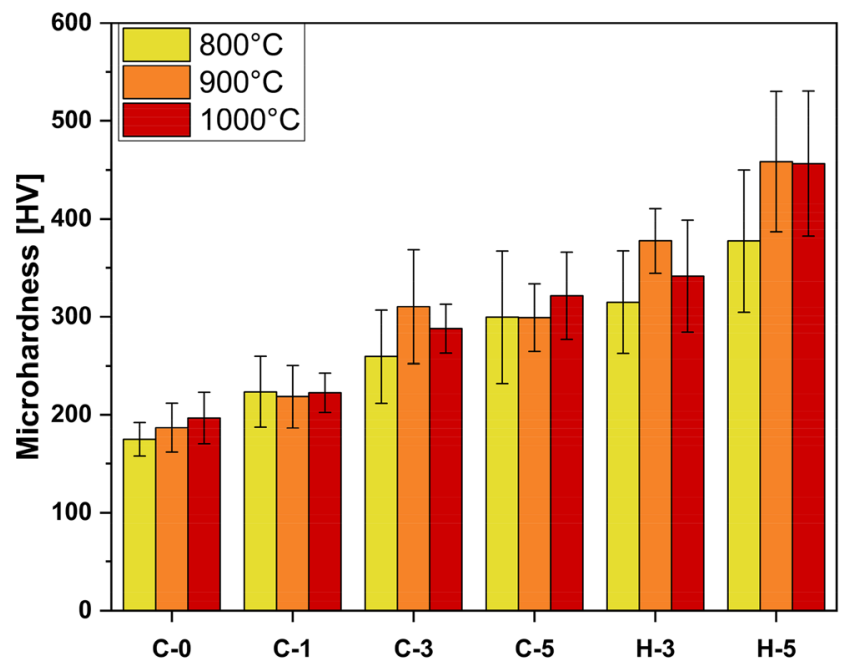

(a)

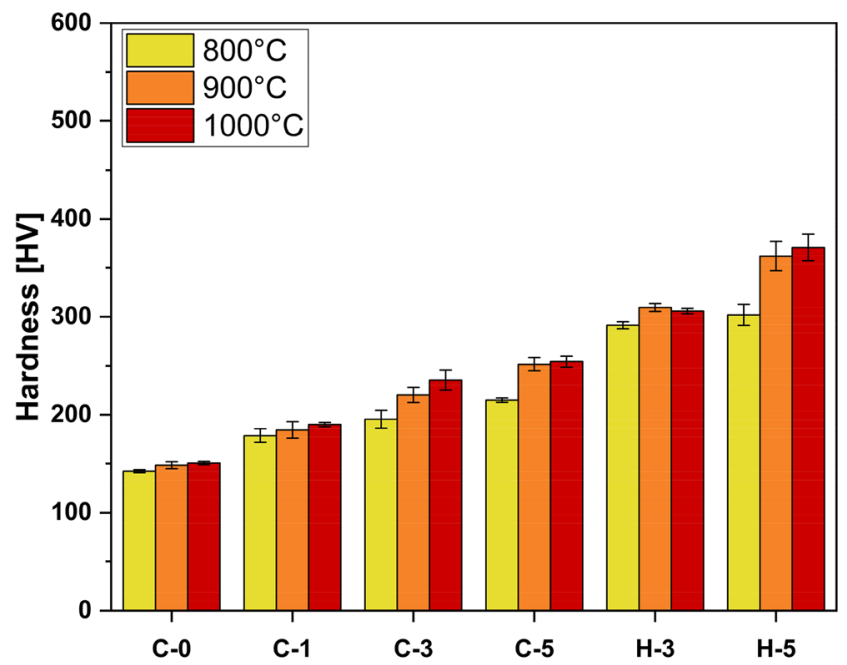

(b)

Figure 7 Microhardness a and converted Vickers hardness $\mathbf{b}$ values of the composites.

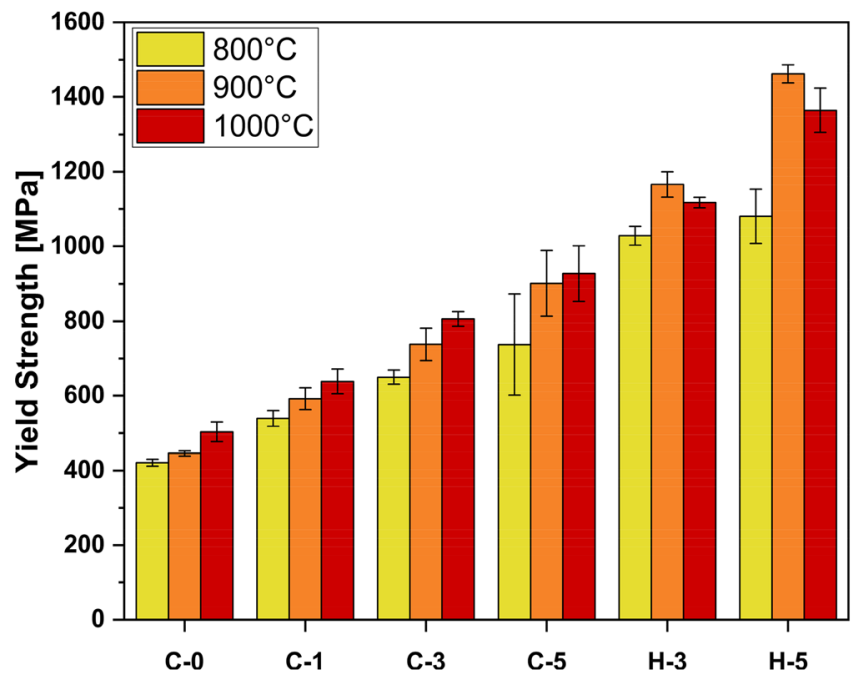

(a)

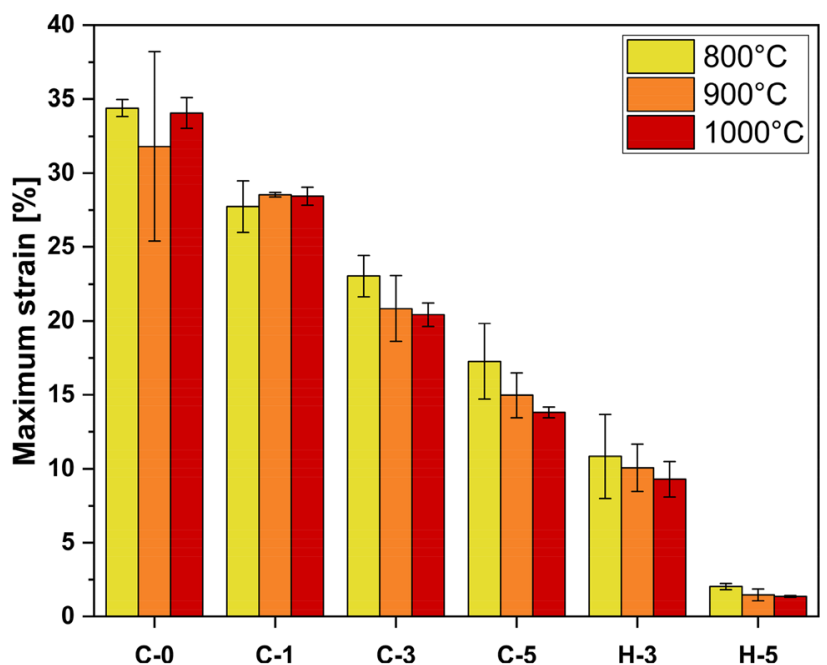

(b)

Figure 8 Yield strength a and maximum strain $\mathbf{b}$ of the composites with different composition.

case of the complete transformation. This means that during each sintering, the content of reinforcements will increase.

According to SEM investigations shown in Fig. 5., the $\mathrm{TiB}_{\mathrm{w}}$ formed in the hybrid composites are shorter and thinner (Fig. 5b) compared to that in the nonhybrid composites (Fig. 5a). The reason behind this effect is the different packing in the hybrid and nonhybrid powder mixtures. In the case of non-hybrid composites, the $\mathrm{Ti}$ and $\mathrm{TiB}_{2}$ particles have direct interfaces only at the edges of the Ti matrix particles, (Fig. 3d); thus, in the middle of the Ti matrix particles, more $\mathrm{TiB}_{2}$ particles stack on each other and develop the $\mathrm{TiB}$ aggregates instead of whiskers. However, in the case of hybrid composites, due to the nanocrystalline $\mathrm{Ti}$, which can be found between the $\mathrm{TiB}_{2}$ particles, thus introducing new $\mathrm{Ti}-\mathrm{TiB}_{2}$ interfaces (Fig. 3e), $\mathrm{TiB}_{\mathrm{w}}$ can be also formed with shortrange diffusion. As a result, significantly more nucleation sites are present allowing to higher number of whiskers, which are thinner and shorter. The presence of more $\mathrm{TiB}_{\mathrm{w}}$ in the hybrid composites might erroneously suggest that an enhancement of the transformation process occurs. However, this enhancement was detectable only in the error range and just in the case of composites sintered at $900{ }^{\circ} \mathrm{C}$. 


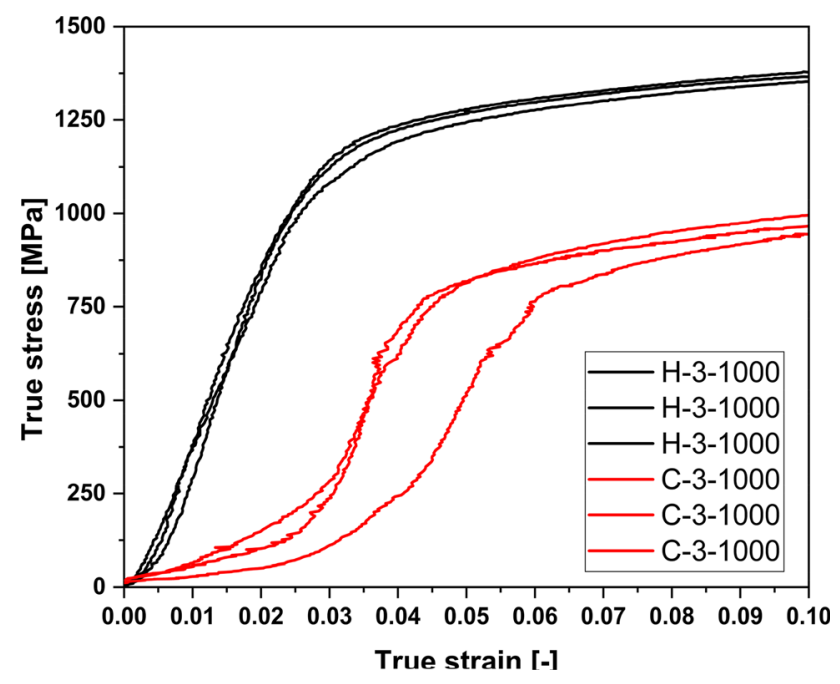

Figure 9 True stress - true strain curves of the parallel three C-3 (red curves) and parallel three $\mathrm{H}-3$ (black curves) hybrid composites sintered at $1000{ }^{\circ} \mathrm{C}$.

The C-5-900 composite had higher $\mathrm{TiB}_{2}$ content $(0.2$ w\% more), while the H-5-900 composite had higher TiB content $(0.4 \mathrm{w} \%)$. On a more realistic approach, the frequency and size/shape of $\mathrm{TiB}_{\mathrm{w}}$ should be related to the physical properties, and not to the weight percentage. At $800{ }^{\circ} \mathrm{C}$, the $\mathrm{XRD}$ indicates barely developed TiB crystals, but all the physical properties are improving compared to the.

C-0 samples. Thus, even a slower, more restricted B diffusion is generating reinforcer phase.

The TiB agglomerates which can be seen in Fig. 5 can also develop when the particles of the matrix are connecting with their surfaces covered with fine $\mathrm{TiB}_{2}$ particles and making stacks on the particle boundaries. However, in our case, most of these agglomerates developed due to the stacking of $\mathrm{TiB}_{2}$ particles in the hollows of the sponge-like Ti matrix. With these kinds of reinforcement phase distribution after a certain time, the $\mathrm{TiB}_{\mathrm{w}}$ will hinder each other in growing and will grow into such agglomerates. Similar phenomena were observed in several studies $[17,25-27]$. It must be noted that in case of the C-5-800, C-5-900 and H-5-800, H-5-900, these layers can also contain unreacted $\mathrm{TiB}_{2}$, which was detected by XRD, but it is not possible to prove by SEM.

The relation of strength and ductility in these composites is the same as in metals in general, namely the higher the yield strength the lower the maximum strain is. The addition of nano-sized $\mathrm{Ti}$ increases both yield strength and hardness of the composites. This increase can be attributed to three different effects, which are given as follows: first, the addition of the extra amount of reinforcing phase as nanocrystalline $\mathrm{Ti}$ in the composition; second, the enhanced $\mathrm{TiB}_{2}$ transformation resulting more $\mathrm{TiB}_{\mathrm{w}}$; third, the strengthening effect of the Ti-O solid solution, which is created by the dissolution of the oxide layers of the initial $\mathrm{TiB}_{2}$ and nanocrystalline $\mathrm{Ti}$ particles into the $\mathrm{Ti}$ matrix. Most probably, these three different factors, through their combined effects influence the changes of the mechanical properties. The strengthening mechanism of the ceramic particles in the non-hybrid and hybrid $\mathrm{Ti}^{-} \mathrm{TiB}_{2}$ composites has several key parameters. The small sized hard ceramic particles, distributed in the soft, large sized matrix particles, will take over a certain amount of external load, hence increasing the yield strength and delaying crack formation. After the cracks have formed, the propagation can go two ways. Either through the soft matrix meanwhile avoiding the hard second phases, or through the second phase, which requires obviously more energy. Due to the whisker type morphology of the second phase, the $\mathrm{TiB}_{\mathrm{w}}$ are present in the composites everywhere; hence, the crack during its propagation will hit a $\mathrm{TiB}_{\mathrm{w}}$ almost immediately. Thus, even after a crack formed, it has to pass through at least one TiB whisker, which will slow down the propagation, hence delaying the failure. This is especially true in the case of hybrid composites, where the numbers of $\mathrm{TiB}_{\mathrm{w}}$ is significantly larger, compared to the non-hybrid composites.

One can see in Fig. 9 that the H-3 curves are overlapping well, as expected from parallel samples; however, there is a small deviation in case of the C-3 composites, where only two of these curves overlap. This difference is most probably contributed to the small inhomogeneities in the composite samples. It was mentioned earlier that the content of the reinforcement phase has a huge effect on mechanical properties. It is especially true in the case of the H-5 composites, where $10 \mathrm{w} \%$ reinforcement phase was added to the matrix in total. Such amount of hard reinforcement phase can lead to brittle behaviour; therefore, it must be noted that the evaluation of these curves is quite complicated. Figure 10. shows the different composition samples sintered at $1000{ }^{\circ} \mathrm{C}$ after the compressive strength test. It can be seen that the samples with more ductility are lower and wider, while the samples with high strength are higher. The H-5-1000 sample is broken into pieces due to the 


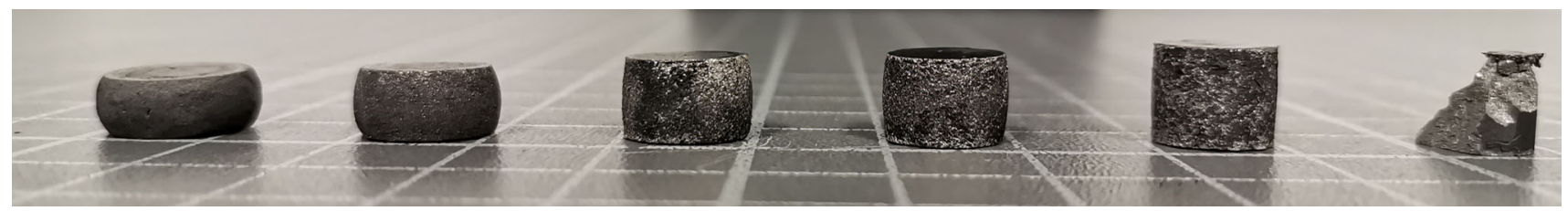

Figure 10 The composites with different composition sintered at $1000{ }^{\circ} \mathrm{C}$ after the compression test (from left to right C-0, C-1, C-3, C-5, $\mathrm{H}-3$, H-5; $1 \mathrm{~mm}$ grid, height of $\mathrm{H} 3$ is $7.47 \mathrm{~mm}$ ).

brittle behaviour caused by the total $10 \mathrm{w} \%$ reinforcement.

It can be also seen that H-3 composites exhibit better mechanical properties, than the C- 5 composites, having only $3 \mathrm{w} \% \mathrm{TiB}_{2}$. Thus, better mechanical properties can be achieved with the addition of $3 \mathrm{w} \%$ $\mathrm{TiB}_{2}$ and $3 \mathrm{w} \%$ nanocrystalline $\mathrm{Ti}$, compared to $5 \mathrm{w} \%$ $\mathrm{TiB}_{2}$. This means, that higher strength can be achieved through exchanging some of the $\mathrm{TiB}_{2}$ to nanocrystalline $\mathrm{Ti}$. This concept can lead to the development of a new area in case of the TiB-reinforced $\mathrm{Ti}$ composite production. By milling, the $\mathrm{Ti}$ particles break up, developing nanoparticles to increase active surface area. In the meantime, crystallite size is also reduced, both intra-particle and particles as free crystallites. While increase in grain surface area increases the number and probability of $\mathrm{TiB}$ nucleation, the nanocrystalline nature will increase crystallisation and growth.

A different variation can be observed in yield strength as a function of sintering temperatures when looking at the $\mathrm{C}$ and $\mathrm{H}$ composites. In the case of $\mathrm{C}$ composites, a linear increase can be observed in yield strength with increasing temperature. On the contrary in the case of $\mathrm{H}$ composites, when increasing the temperature, the yield strength changes with a maximum versus temperature, peaking at $900{ }^{\circ} \mathrm{C}$ due to particle distribution issues. It was shown by SEM that the $\mathrm{TiB}_{2}$ and nanocrystalline Ti particles fill up the hollows of the sponge-like Ti matrix (Fig. 3e). Thus, for the transformation described by Eq. 1, a certain part of the required titanium is most probably provided by the nanocrystalline $\mathrm{Ti}$ because these particles are the closest to the $\mathrm{TiB}_{2}$ particles, especially in the middle part of the hollows. Hence, during sintering, the nanocrystalline Ti content decreases as the $\mathrm{TiB}$ formation proceeds. It is evident that the higher the sintering temperature is, the faster the reaction is. As a consequence, sintering at $1000{ }^{\circ} \mathrm{C}$ will have less nanocrystalline $\mathrm{Ti}$ content than sintering at $900{ }^{\circ} \mathrm{C}$. Since the high yield strength of the $\mathrm{H}$ composites is due to the $\mathrm{TiB}_{2}$ and nanocrystalline $\mathrm{Ti}$ and $\mathrm{TiB}$ phases, it is clear that the mechanical properties of $1000{ }^{\circ} \mathrm{C}$ sintering decrease due to the lower amount of nano-sized $\mathrm{Ti}$ which is not compensated by the higher amount of formed TiB. This proves that the content of the nanocrystalline Ti phase also has a major role in the mechanical properties besides the formed TiB phase. It also must be noted that the mechanical properties (both yield strength and hardness) are inversely proportional to the results of the relative density. This means that the hybrid composites have the lowest relative density values, yet, they have improved mechanical properties compared to the non-hybrid composites. However, relative density can be connected to the maximum strain values, where the same tendency can be observed: increasing the amount of reinforcement phases results in the lowest relative density and the lowest maximum strain values, which is logical, since the samples with the most material discontinuities will be the less formable before failure. Of course, considering the application areas (cutting tools, high strength-lightweight components), the composites should have the highest achievable relative density; on the other hand, in some areas, porous composites are also required [28]. Nevertheless, to achieve denser composites, some of the process parameters should be varied; for example, the applied pressure during the cold pressing should be higher than $1.5 \mathrm{GPa}$, and sintering temperature should exceed $1000{ }^{\circ} \mathrm{C}$ with increased sintering time. However, the sintering time and temperature must be chosen to avoid the coarsening of the nanocrystalline Ti.

It must be noted that the brittle behaviour of the $\mathrm{H}-5$ composites is most probably caused by the stacking of brittle particles ( $\mathrm{TiB}_{2}, \mathrm{TiB}$, nano-sized $\mathrm{Ti}$ ) in the hollows during the mixture making progress of the $\mathrm{Ti}^{-} \mathrm{TiB}_{2}$-nanoTi composites. Table 3. compares the yield strength and hardness values measured in this and other literature studies. 
Table 3 The yield strength determined with compressive test and the measured microhardness and hardness values of this and other studies in the literature*

\begin{tabular}{|c|c|c|c|c|c|}
\hline Material & Method & $\begin{array}{l}\text { Sintering temperature } \\
\left({ }^{\circ} \mathrm{C}\right)\end{array}$ & $\begin{array}{l}\text { Yield strength } \\
\text { (MPa) }\end{array}$ & $\begin{array}{l}\text { Hardness Microhardness } \\
(\mathrm{HV})\end{array}$ & Source \\
\hline Ti-5 w\% $\mathrm{TiB}_{2}$ & PM & 1000 & 927 & $\begin{array}{l}254 \\
321_{\mathrm{mh}}\end{array}$ & $\begin{array}{l}\text { This } \\
\text { work }\end{array}$ \\
\hline $\begin{array}{l}\text { Ti-3 w\% } \mathrm{TiB}_{2}-3 \text { w\% nano-sized } \\
\text { Ti }\end{array}$ & & 900 & 1166 & $\begin{array}{l}310 \\
378_{\mathrm{mh}}\end{array}$ & \\
\hline $\begin{array}{l}\text { Ti-5 w\% } \mathrm{TiB}_{2}-5 \text { w\% nano-sized } \\
\mathrm{Ti}\end{array}$ & & 900 & 1461 & $\begin{array}{l}362 \\
458_{\mathrm{mh}}\end{array}$ & \\
\hline $\mathrm{Ti}-5 \mathrm{w} \% \mathrm{TiB}_{2}$ & $\begin{array}{l}\text { SLM } \\
\text { Casting } \\
\text { PM }\end{array}$ & $\begin{array}{l}- \\
- \\
1100\end{array}$ & $\begin{array}{l}1103 \\
815 \\
318\end{array}$ & $\begin{array}{l}402_{\mathrm{mh}} \\
404_{\mathrm{mh}} \\
308_{\mathrm{mh}}\end{array}$ & $\begin{array}{l}{[29]} \\
{[30]}\end{array}$ \\
\hline Ti-5 w\% B $\mathrm{B}_{4} \mathrm{C}$ & SLM & - & - & $425_{\mathrm{mh}}$ & [31] \\
\hline $\begin{array}{l}\text { Ti-4.8 w\% } \% \mathrm{TiB}_{2} \\
\text { Ti-9.6 w\% } \mathrm{TiB}_{2}\end{array}$ & SPS & 1050 & - & $\begin{array}{l}477_{\mathrm{mh}} \\
586_{\mathrm{mh}}\end{array}$ & [13] \\
\hline Ti-9.6 w\% $\mathrm{TiB}_{2}$ & SPS & 1050 & - & 404 & [32] \\
\hline
\end{tabular}

*The abbreviation of the processes: PM-Powder Metallurgy, SLM-Selective Laser Melting, SPS-Spark Plasma Sintering, RHP-Reactive Hot Pressing; the ${ }_{\text {mh }}$ letters next to the numbers denotes that value was measured by microhardness measurement

It can be seen that the H-3 sample showed higher strength values than the C- 5 composites produced in this work and produced by Attar et al. [28]. Since in most of the composites the same phases $\left(\mathrm{TiB}, \mathrm{TiB}_{2}, \alpha\right.$ or $\beta \mathrm{Ti}$ ) could be mostly observed, it is not surprising that the compared hardness values are not far from each other, obviously only in case of similar composition. Also, the hardness values are independent on the processing method but highly depend on the quality and quantity of the reinforcement phase. In case of the yield strength, significant differences can be observed even in case of similar compositions due to the different processing method. It can be seen that the highest hardness values were achieved with the SPS method [13, 32]; the second best method to achieve high hardness is the SLM technique [29, 31], which is followed by the standard PM method [30] and the casting method [30]. It should be noted that the hardness values of the hybrid composites produced by PM in this work are similar to the hardness values of the composites produced by SPS technique. Therefore, it can be said that, the effect of the different processing methods manifests, however the main influencer of the mechanical properties remains the quantity of the reinforcing phase.

The mechanical properties of these novel hybrid composites produced in this research make these types of composites a competitor to similar composites presented in the literature. A promising field of application with high requirements is the biomedical area [33], which generally requires porous, low-density materials. Furthermore, the addition of nano-sized $\mathrm{Ti}$ into the traditional Ti-based $\mathrm{TiB}_{2}-$ reinforced materials is giving an option to reconsider the composition and the content of raw materials used to create them and also opens new possibilities in the composite production. Due to the nanocrystalline $\mathrm{Ti}$ content, the applied $\mathrm{TiB}_{2}$ content can be decreased in the $\mathrm{Ti}^{-} \mathrm{TiB}_{2}$ composites and not just preserving the required and ordinary mechanical properties of these kind of composites but further improving them.

\section{Conclusions}

Novel TiB and nanocrystalline Ti-reinforced hybrid composites were developed. Compositions of $\mathrm{Ti}$ matrix $+3 \mathrm{w} \% \mathrm{TiB}_{2}+3 \mathrm{w} \%$ nano-sized $\mathrm{Ti}$ and $\mathrm{Ti}$ matrix $+5 \mathrm{w} \% \quad \mathrm{TiB}_{2}+5 \mathrm{w} \%$ nano-sized $\mathrm{Ti}$ were successfully fabricated by the powder metallurgy route, with vacuum sintering at $800{ }^{\circ} \mathrm{C}, 900{ }^{\circ} \mathrm{C}$ and $1000{ }^{\circ} \mathrm{C}$.Based on the obtained results, the following novelties can be concluded.

(1) $\mathrm{The} \mathrm{TiB}_{2} \rightarrow \mathrm{TiB}$ transformation was completed at $1000{ }^{\circ} \mathrm{C}$ after $2 \mathrm{~h}$ of sintering; however, at 
$800{ }^{\circ} \mathrm{C}$ and $900{ }^{\circ} \mathrm{C}$, residual $\mathrm{TiB}_{2}$ is still detected. Nevertheless, a change in the $\mathrm{TiB}_{2-}$ $\rightarrow$ TiB transformation was observed in case of the hybrid H-5-900 composites compared to the non-hybrid C-5-900 composite, as a beneficial effect of milling on nucleation and whisker growth.

(2) The hybrid composites fabricated in this study exhibited higher yield strength and hardness, and significantly lower ductility then the nonhybrid composites proving that, with less $\mathrm{TiB}_{2}$ content and addition of nano-sized Ti can lead to higher mechanical properties compared to traditional $\mathrm{Ti}^{-} \mathrm{TiB}_{2}-\mathrm{TiB}$ composites without nano-sized Ti. Therefore, this hybrid composition can be a new area in TiB-reinforced composites' production.

(3) These new hybrid composites can be used in the same fields (military equipments, cutting tools, material used at high temperature applications) as other $\mathrm{Ti}^{-} \mathrm{TiB}_{2}$ composites, however, with lower production cost (due to the less $\mathrm{TiB}_{2}$ content requirement) and easier recycling possibilities (due to the less $\mathrm{TiB}_{2}$ and $\mathrm{TiB}$ content).

\section{Acknowledgements}

The authors would like to thank the help of Dr. Dániel Koncz-Horváth for the SEM examinations. The described article was carried out as part of the GINOP-2.3.2-15-2016-00027 "Sustainable operation of the workshop of excellence for the research and development of crystalline and amorphous nanostructured materials" project implemented in the framework of the Szechenyi 2020 program. The realization of this project is supported by the European Union. The research work of David Adam Angel was supported by the ÚNKP-20-3 New National Excellence Program of the Ministry for Innovation and Technology from the source of the National Research, Development and Innovation Fund. This work of Marton Benke was financed by the UMA3 project, which has received funding from the European Union's Horizon 2020 research and innovation program under Grant Agreement No 952463.

\section{Funding}

Open access funding provided by University of Miskolc.

\section{Declarations}

Conflict of interest The authors declare that they have no known competing interests.

Open Access This article is licensed under a Creative Commons Attribution 4.0 International License, which permits use, sharing, adaptation, distribution and reproduction in any medium or format, as long as you give appropriate credit to the original author(s) and the source, provide a link to the Creative Commons licence, and indicate if changes were made. The images or other third party material in this article are included in the article's Creative Commons licence, unless indicated otherwise in a credit line to the material. If material is not included in the article's Creative Commons licence and your intended use is not permitted by statutory regulation or exceeds the permitted use, you will need to obtain permission directly from the copyright holder. To view a copy of this licence, visit http://creativecommons.org/licen ses/by $/ 4.0 /$.

\section{References}

[1] Tjong SC, Ma ZY (2000) Microstructural and mechanical characteristics of in situ metal matrix composites. Mater Sci Eng R 29:49-113. https://doi.org/10.1016/S0927-796X(00) 00024-3

[2] Norgate TE, Wellwood G (2006) The potential applications for titanium metal powder and their life cycle impacts. J Min Met Mat S 58:58-63. https://doi.org/10.1007/s11837-006-0 084-y

[3] Geetha M, Singh AK, Asokamani R, Gogia AK (2009) Ti based biomaterials, the ultimate choice for orthopaedic implants - A review. Prog Mater Sci 54:397-425. https://doi. org/10.1016/j.pmatsci.2008.06.004

[4] Elias CN, Meyers MA, Valiev RZ, Monteiro SN (2013) Ultrafine grained titanium for biomedical applications: an overview of performance. J Mater Res Tech 2:340-350. h ttps://doi.org/10.1016/j.jmrt.2013.07.003

[5] Basu B, Raju GB, Suri AK (2006) Processing and properties of monolithic $\mathrm{TiB}_{2}$ based materials. Int Mater Rev 51:352-374. https://doi.org/10.1179/174328006X102529 
[6] Munro RG (2000) Material properties of titanium diboride. J Res of the Natl Inst Stan 105:709-720. https://doi.org/10. 6028/jres.105.057

[7] Ravichandran KS, Panda KB, Sahay SS (2004) TiBw-reinforced Ti composites: Processing, properties, application prospects, and research needs. J Min Met Mat S 56:42-48. h ttps://doi.org/10.1007/s11837-004-0127-1

[8] Alman DE, Hawk JA (1999) The abrasive wear of sintered titanium matrix-ceramic particle reinforced composites. Wear 225-229:629-639. https://doi.org/10.1016/s0043-164 $8(99) 00065-4$

[9] Saito T (2004) The automotive application of discontinuously reinforced TiB-Ti composites. J Min Met Mat S 56:33-36. https://doi.org/10.1007/s11837-004-0125-3

[10] Yi M, Zhang X, Liu G, Wang B, Shao H, Qiao G (2018) Comparative investigation on microstructures and mechanical properties of $(\mathrm{TiB}+\mathrm{TiC}) / \mathrm{Ti}-6 \mathrm{Al}-4 \mathrm{~V}$ composites from Ti-B ${ }_{4} \mathrm{C}-\mathrm{C}$ and $\mathrm{Ti}^{-} \mathrm{TiB}_{2}-\mathrm{TiC}$ systems. Mater Charact 140:281-289. https://doi.org/10.1016/j.matchar.2018.04.010

[11] Li DX, Ping DH, Lu YX, Ye HQ (1993) Characterization of the microstructure in TiB-whisker reinforced Ti alloy matrix composite. Mater Lett 16:322-326. https://doi.org/10.1016/ 0167-577X(93)90201-8

[12] Lu W, Zhang D, Zhang X, Wu R, Sakata T, Mori H (2001) HREM study of $\mathrm{TiB} / \mathrm{Ti}$ interfaces in a TiB-TiC in situ composite. Scripta Mater 44:1069-1075. https://doi.org/10. 1016/S1359-6462(01)00663-7

[13] Namini AS, Azadbeh M, Asl MS (2017) Effect of $\mathrm{TiB}_{2}$ content on the characteristics of spark plasma sintered $\mathrm{Ti}-$ TiBw composites. Adv Powder Technol 28:1564-1572. h ttps://doi.org/10.1016/j.apt.2017.03.028

[14] Mohammadzadeh A, Azadbeh M, Danninger H, Namini AS (2020) $\mathrm{Ti}^{-} \mathrm{TiB}_{2}$ composites consolidated by spark plasma sintering: reaction mechanism, characteristics of in-situ formed phases and densification behavior. Mater Chem Phys 242:122556. https://doi.org/10.1016/j.matchemphys.2019. 122556

[15] Liu L, Minasyan T, Ivanov R, Aydinyan S, Hussainova I (2020) Selective laser melting of $\mathrm{TiB}_{2}$-Ti composite with high content of ceramic phase. Ceram Int 46:21128-21135. h ttps://doi.org/10.1016/j.ceramint.2020.05.189

[16] Atri RR, Ravichandran KS, Jha SK (1999) Elastic properties of in-situ processed Ti-TiB composites measured by impulse excitation of vibration. Mater Sci Eng A 271:150-159. h ttps://doi.org/10.1016/S0921-5093(99)00198-7

[17] Sahay SS, Ravichandran KS, Atri RR, Chen B, Rubin J (1999) Evolution of microstructure and phases in in situ processed $\mathrm{Ti}-\mathrm{TiB}$ composites containing high volume fractions of TiB whiskers. J Mater Res 14:4214-4223. https://d oi.org/10.1557/JMR.1999.0571
[18] Mikó T, Kristály F, Pethő D, Svéda M, Karacs G, Gergely G, Gácsi Z, Roósz A (2021) Investigation of nanocrystalline sintered W-25 w\% Cu composite. Int J Refract Met $\mathrm{H}$ 95:105438. https://doi.org/10.1016/j.ijrmhm.2020.105438

[19] Young RA (1995) The rietveld method. Oxford University Press

[20] Dinnebier RE, Leineweber A, Evans JSO (2018) Rietveld refinement: practical powder diffraction pattern analysis using TOPAS. De Gruyter. https://doi.org/10.1515/ 9783110461381

[21] McCusker LB, Von Dreele RB, Cox DE, Louër D, Scardi P (1999) Rietveld refinement guidelines. J App Crystallogr 32:36-50. https://doi.org/10.1107/S0021889898009856

[22] Wang G, Li J, Lv K, Zhang W, Ding X, Yang G, Liu X, Jiang $X$ (2016) Surface thermal oxidation on titanium implants to enhance osteogenic activity and in vivo osseointegration. Sci Rep-UK 6:31769. https://doi.org/10.1038/srep31769

[23] Liu X, Chu PK, Ding C (2004) Surface modification of titanium, titanium alloys, and related materials for biomedical applications. Mat Sci Eng R 47:49-121. https://doi.org/ 10.1016/j.mser.2004.11.001

[24] Hardness conversion chart -https://steelselector.sij.si/calcula tors/hardness/hardness_table.html. Accessed 29 July 2021

[25] Panda KB, Ravi Chandran KS (2003) Titanium-titanium boride (Ti-TiB) functionally graded materials through reaction sintering: Synthesis, microstructure, and properties. Metall Mater Trans A 34:1993-2003. https://doi.org/10.100 7/s11661-003-0164-3

[26] Huang LJ, Yang FY, Hu HT, Rong XD, Geng L, Wu LZ (2013) TiB whiskers reinforced high temperature titanium Ti60 alloy composites with novel network microstructure. Mater Design 51:421-426. https://doi.org/10.1016/j.matdes. 2013.04.048

[27] Feng H, Meng Q, Zhou Y, Jia D (2005) Spark plasma sintering of functionally graded material in the $\mathrm{Ti}-\mathrm{TiB}_{2}-\mathrm{B}$ system. Mat Sci Eng A 397:92-97. https://doi.org/10.1016/j. msea.2005.02.003

[28] Attar H, Löber L, Funk A, Calin M, Zhang LC, Prashanth KG, Scudino S, Zhang YS, Eckert J (2015) Mechanical behavior of porous commercially pure $\mathrm{Ti}$ and $\mathrm{Ti}-\mathrm{TiB}$ composite materials manufactured by selective laser melting. Mat Sci Eng A 625:350-356. https://doi.org/10.1016/j.msea. 2014.12.036

[29] Attar H, Bönisch M, Calin M, Zhang LC, Scudino S, Eckert J (2014) Selective laser melting of in situ titanium-titanium boride composites: Processing, microstructure and mechanical properties. Acta Mater 76:13-22. https://doi.org/10.101 6/j.actamat.2014.05.022

[30] Attar H, Bönisch M, Calin M, Zhang LC, Zhuravleva K, Funk A, Scudino S, Yang C, Eckert J (2014) Comparative 
study of microstructures and mechanical properties of in situ Ti-TiB composites produced by selective laser melting, powder metallurgy, and casting technologies. J Mater Res 29:1941-1950. https://doi.org/10.1557/jmr.2014.122

[31] Han C, Rita B, Chua JDQ, Ramamurty U, Tor SB, Sun CN, Zhou K (2020) Microstructure and mechanical properties of $(\mathrm{TiB}+\mathrm{TiC}) / \mathrm{Ti}$ composites fabricated in situ via selective laser melting of $\mathrm{Ti}$ and $\mathrm{B}_{4} \mathrm{C}$ powders. Addit Man 36:101466. https://doi.org/10.1016/j.addma.2020.101466

[32] Namini AS, Dilawary SAA, Motallebzadeh A, Asl MS (2019) Effect of $\mathrm{TiB}_{2}$ addition on the elevated temperature tribological behavior of spark plasma sintered Ti matrix composite. Compos Part B-Eng 172:271-280. https://doi.or g/10.1016/j.compositesb.2019.05.073

[33] Otte JA, Zou J, Patel R, Lu M, Dargusch MS (2020) TiB nanowhisker reinforced titanium matrix composite with improved hardness for biomedical applications. Nanomaterials 10:2480. https://doi.org/10.3390/nano10122480

Publisher's Note Springer Nature remains neutral with regard to jurisdictional claims in published maps and institutional affiliations. 